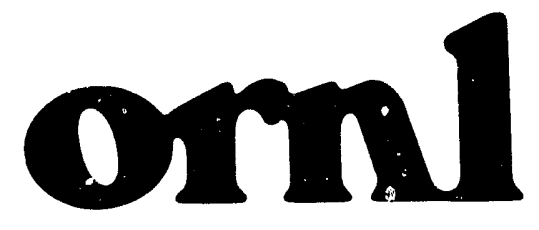

OAK RIDGE

NATIONAL

LABORATORY

MARTIN MARUETIA
Megu:

SEP 271991

\author{
A Short Report on \\ Voltage-to-Frequency \\ Conversion for HISTRAP RF \\ System Tuning Control Loops
}

A. M. Hasanul Basher
MANAGED BY

MARTIN MARIETTA ENERGY SYSTEMS, INC.

FOP THE UATTES STATES

DEPARTMENT OF ENERGY 
This report has been reproduced directly from the best available copy.

Available to DOE and DOE contractors from the Office of Scientific and Technical Information, P.O. Box 62, Oak Ridge, TN 37831; prices available from (615) 576-8401, FTS 626-8401.

Available to the public from the National Technical Information Service, U.S. Department of Commerce, 5285 Port Royal Rd., Springfield, VA 22161.

This report was prepared as an account of work sponsored by an agency of the United States Government. Neither the United States Government nor any agency thereof, nor any of their employees, makes any warranty, express or implied, or assumes any legal liability or responsibility for the accuracy, completeness, or usefulness of any information, apparatus, product, or process disclosed, or represents that its use would not infringe privately owned rights. Reference herein to any specific commercial product, process, or service by trade name, trademark, manufacturer, or otherwise, does not necessarily constitute or imply its endorsement, recommendation, or favoring by the United States Government or any agency thereot. The views and opinions of authors expressed herein do not necessarily state or reflect those of the United States Government or any agency thereof. 
Physics Division

\title{
A SHORT REPORT ON VOLTAGE-TO-FREQUENCY CONVERSION FOR HISTRAP RF SYSTEM TUNING CONTROL LOOPS
}

\author{
A. M. Hasanul Basher \\ Manuscript Completed-August 17, 1990 \\ Date Published-September 1991
}

NOTICE: This document contains information of a preliminary nature. It is subject to revision or correction and therefore does not represent a final report.

\author{
Prepared for the \\ Office of Energy Research \\ KB 0202000 \\ Prepared by the \\ Oak Ridge National Laboratory \\ Oak Ridge, Tennessee 37831-6285 \\ managed by \\ MARTIN MARIETTA ENERGY SYSTEMS, INC. \\ for the \\ U.S. DEPARTMENT OF ENERGY \\ under contract DE-AC05-84OR21400
}




\author{
A SHORT REPORT ON \\ VOLTAGE-TO-FREQUENCY CONVERSION \\ FOR \\ HISTRAP RF SYSTEM TUNING CONTROL LOOPS*
}

\author{
A. M. Hasanul Basher ${ }^{1}$ \\ Physics Division \\ Oak Ridge National Laboratory \\ Oak Ridge, Tennessee 37831-6368
}

August 17, 1990

* Research sponsored by the U.S. Department of Energy under contract DE-AC05-84OR21400 with Martin Marietta Energy Systems, Inc.

1 Summer Faculty Research Participant, School of Engineering Technology, South Carolina State College, Orangeburg, South Carolina 29117.

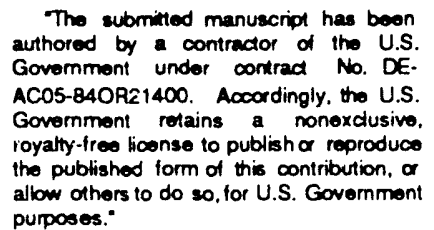




\section{TABLE OF CONTENTS}

Page

$\begin{array}{lr}\text { Introduction } & 1\end{array}$

Implementation Strategy 2

HISTRAP RF System Tuning Control Loops Block Diagram 3

Hardware Configuration 4

Specifications $\quad 5$

Flowcharts $\quad 6$

$\begin{array}{ll}\text { Results: Execution Time } & 15\end{array}$

Solution: Meeting the Requirements 20

Appendix A: Program Listings $\quad 24$

Appendix B: Special Notes $\quad 25$

$\begin{array}{ll}\text { Distribution } & 26\end{array}$ 


\section{ACKNOWLEDGEMENTS}

This program was sponsored by Oak Ridge Associated Universities (ORAU) and conducted under the supervision of S. W. Mosko in the Physics Division at ORNL. I greatly appreciate ORAU for giving me an opportunity to work on this project. I wish to express my gratitude to my supervisor, S. W. Mosko, for his invaluable suggestions and proper guidance in carrying out this project.

I would like to thank several other members of the Physics Division who helped me by providing advice and discussing problems on various occasions. They are D. K. Olsen, R. C. Juras, and B. A. Tatum. I would also like to thank the staff members in the instrument shop for their help and cooperation.

I am also indebted to Ms. Jeanette McBride for her assistance in organizing and editing the report. 


\section{INTRODUCTION}

One of the requirements of the HISTRAP RF accelerating system is that the frequency of the accelerating voltage for the cavity must keep in step with the change in the magnetic field. As the energy of the particle increases, the magnetic field is increased to keep the radius of the particle orbit constant. At the same time, the frequency of the electric field must be changed to insure that it is synchronized with the angular movement of the particle. So we need to generate the frequency of the accelerating voltage in relation to the magnetic field.

The frequency generation can be accomplished in two stages. The first stage of frequency generation consists of measuring the magnetic field in terms of voltage which is already developed. The second stage is to convert this voltage into frequency. Final frequency precision can be achieved by deriving a frequency-correcting signal from the beam position.

This project is concerned with generating the frequency from the analog voltage. The speed of response required will place very stringent requirements on both hardware and software. Technology is available to carry out this task. A hardware configuration has been established and software has been developed.

In the following sections, we describe the implementation strategy, the hardware configuration, and the desired specifications. Next, we present the software developed, results obtained, along with capabilities and limitations of the system. Finally, we suggest alternate solutions to overcome some of the limitations toward meeting our goal. In the appendices, we include program listings. 


\section{IMPLEMENTATION STRATEGY}

The implementation of frequency generation from, voltage will be carried out in three steps shown below:

1. Convert the analog signal (voltage) into digital signal.

2. Compute the frequency value that corresponds to the digital signal.

3. Generate the signal taking'frequency value computed in step 2.

Conversion of analog voltage to digital can be done with the help of an analog-to-digital converter. A high sampling rate is desirable for the precise measurement of the instantaneous value of the analog input.

CPU will be used for the frequency value computation.

A frequency synthesizer capable of generating glitch-free signal and having reasonably fast switching characteristics over the desired frequency range will be utilized to accomplish the third step above.

A software program will be written to aid the CPU communicating with the analog-to-digital converter and the frequency synthesizer. In developing the software, care must be taken so the execution time can be kept at a minimum. 
HISTRAP RE SYSTEM TUNING CONTROLLLOPS

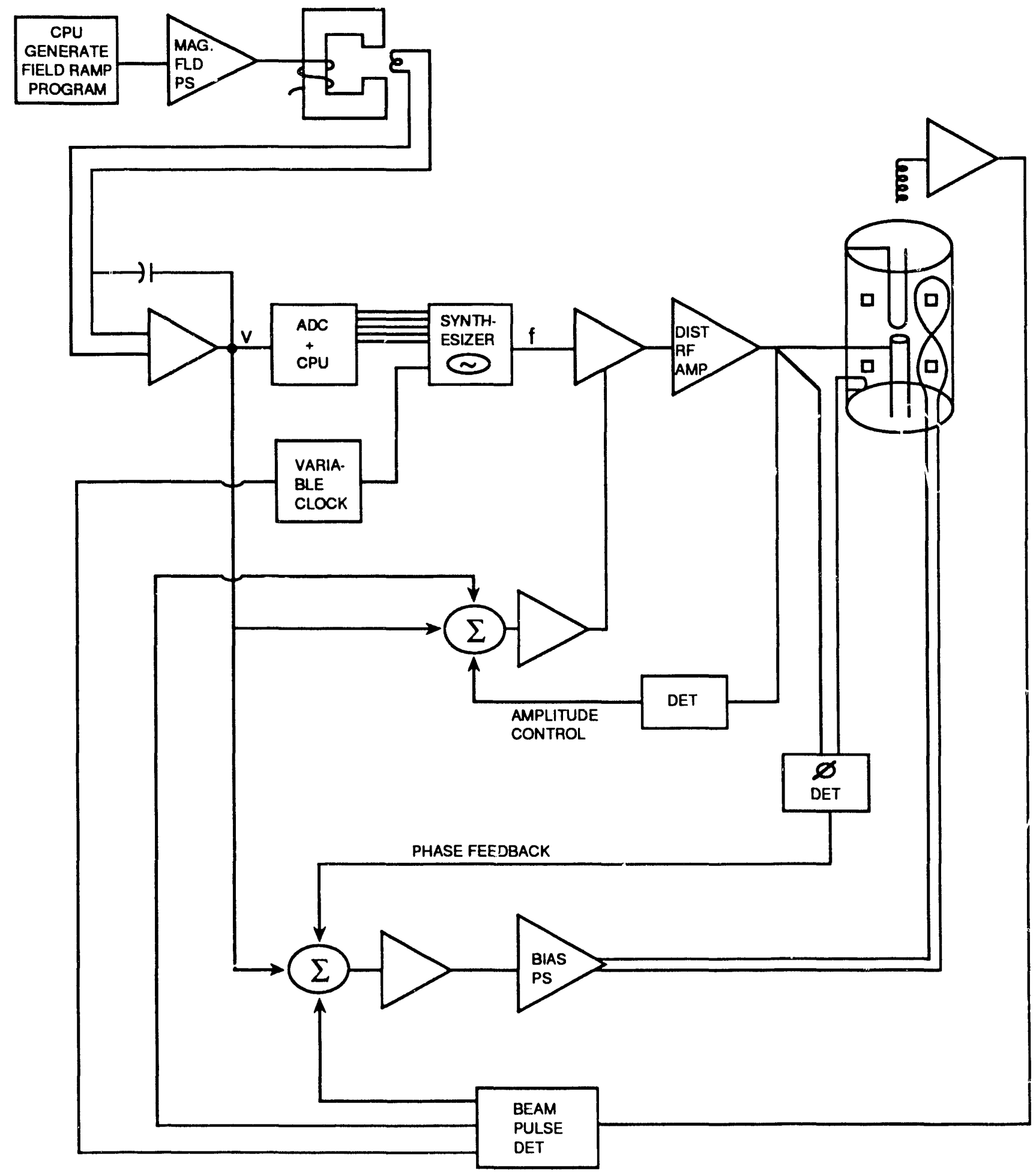




\section{HARDWARE CONFIGURATION}

\section{Hardware}

a. Analog-to-Digital Converter

$$
\text { DT2814 }
$$

12-bit resolution

$25 \mu \mathrm{s}$ A/D conversion time

b. $\mathrm{CPU}$

IBM-PC or compatible

c. Frequency synthesizer

HP 3325A

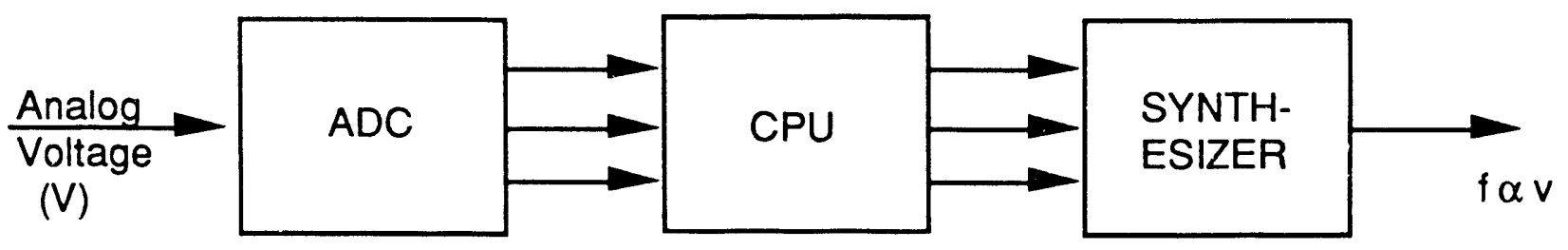

\section{Software}

Written in Assembly language 


\section{SPECIFICATIONS}

$\begin{array}{llll}\text { 1. } & \text { Frequency range } & - & 0.2 \text { to } 2.7 \mathrm{MHz} \\ \text { 2. Sampling interval } & - & 10 \mu \mathrm{s} \\ \text { 3. } & \frac{\Delta f}{\mathrm{f}} & - & <2 \times 10^{-4}\end{array}$

1. Frequency range can be achieved without much difficulty.

2. This small sampling interval places very strict requirements on both hardware and software.

3. Frequency precision can be achieved by a correcting signal taken from the beam. 


\section{ELOWCHARTS}

This section includes the flowcharts of the programs writte.1, as well as initialization procedure for interrupt. Important segments of the program are also explained in detail. It covers the following:

1. Voltage-to-frequency conversion

Without interrupt

On interrupt basis

2. Look-up table generation

3. Frequency address calculation

4. ADC output read

5. Initialization for interrupts

6. Some program segments 


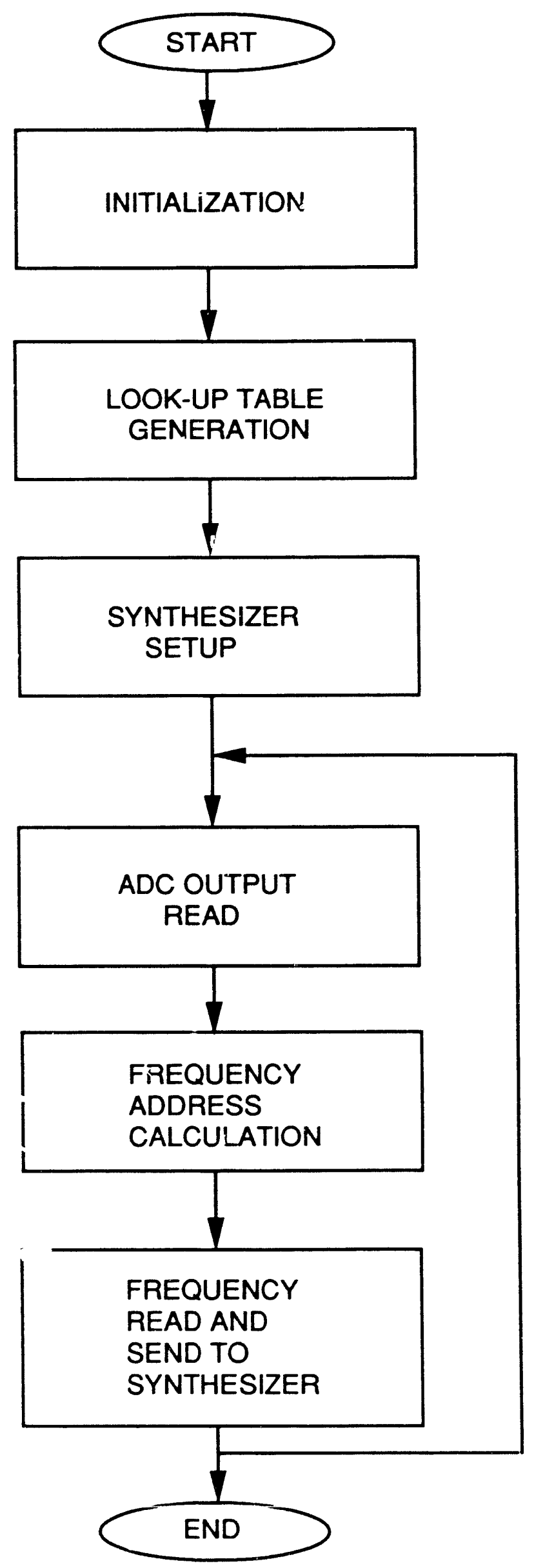


ON INTERRUPT BASIS

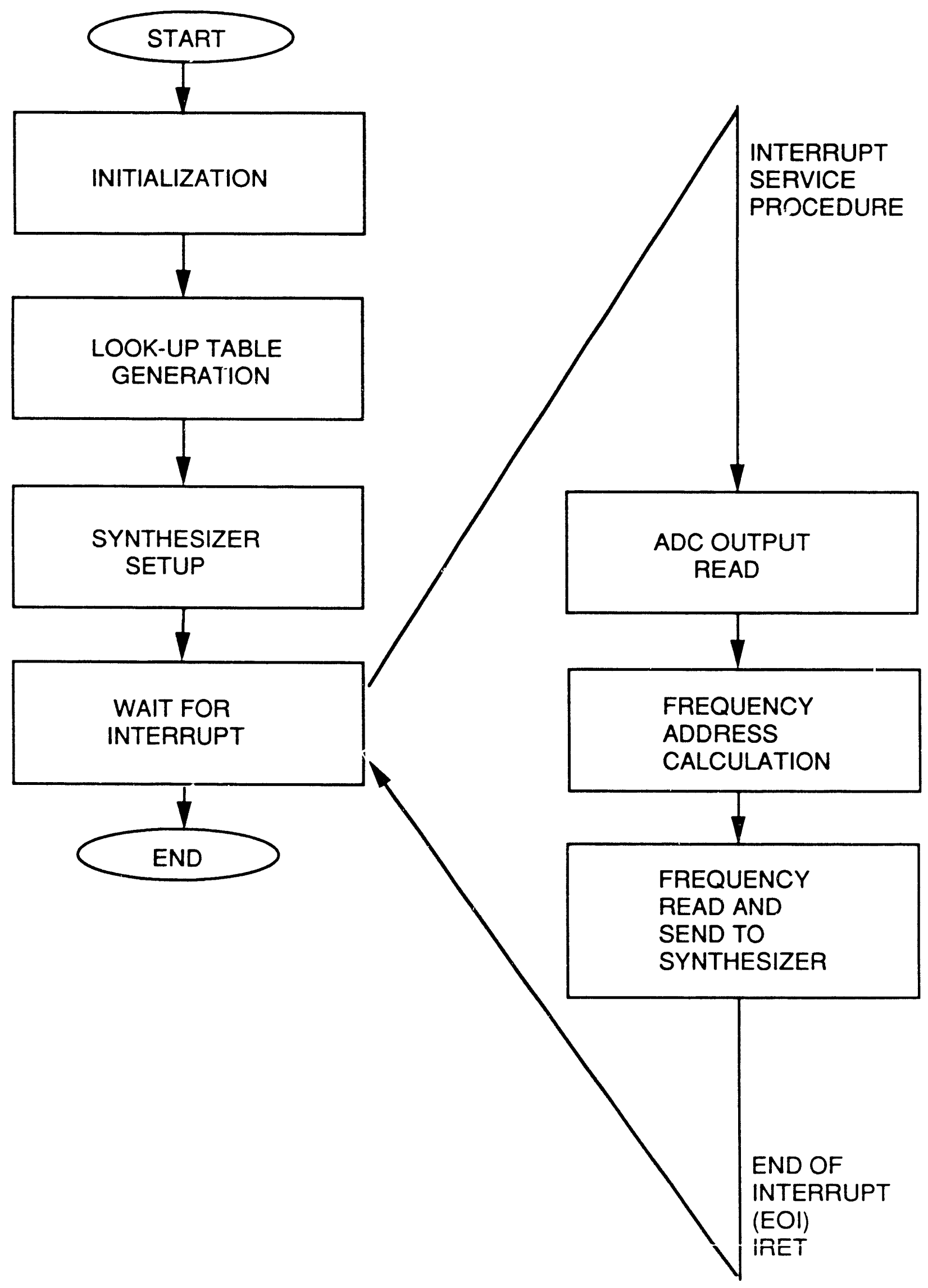




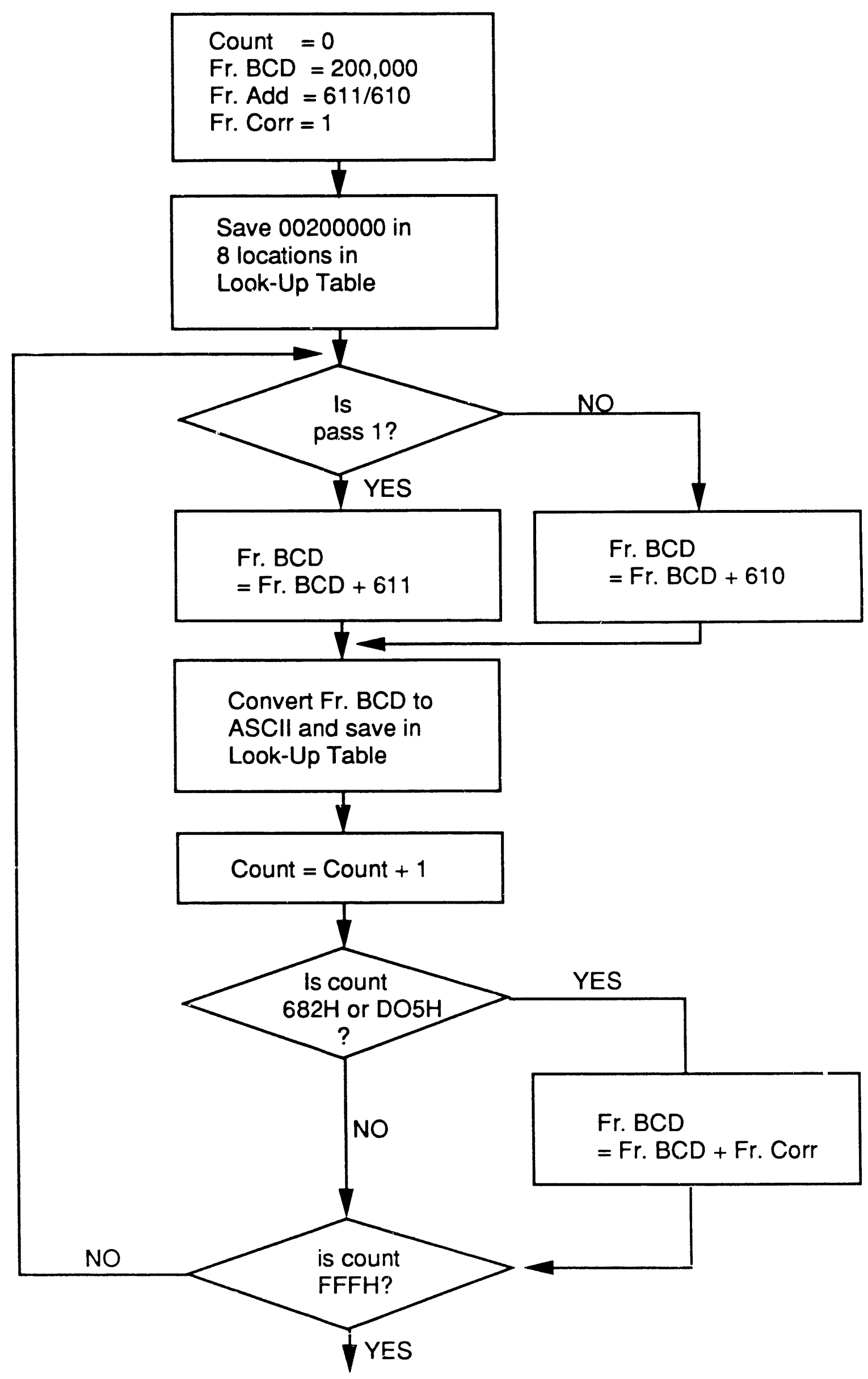


ADC OUTPUT READ

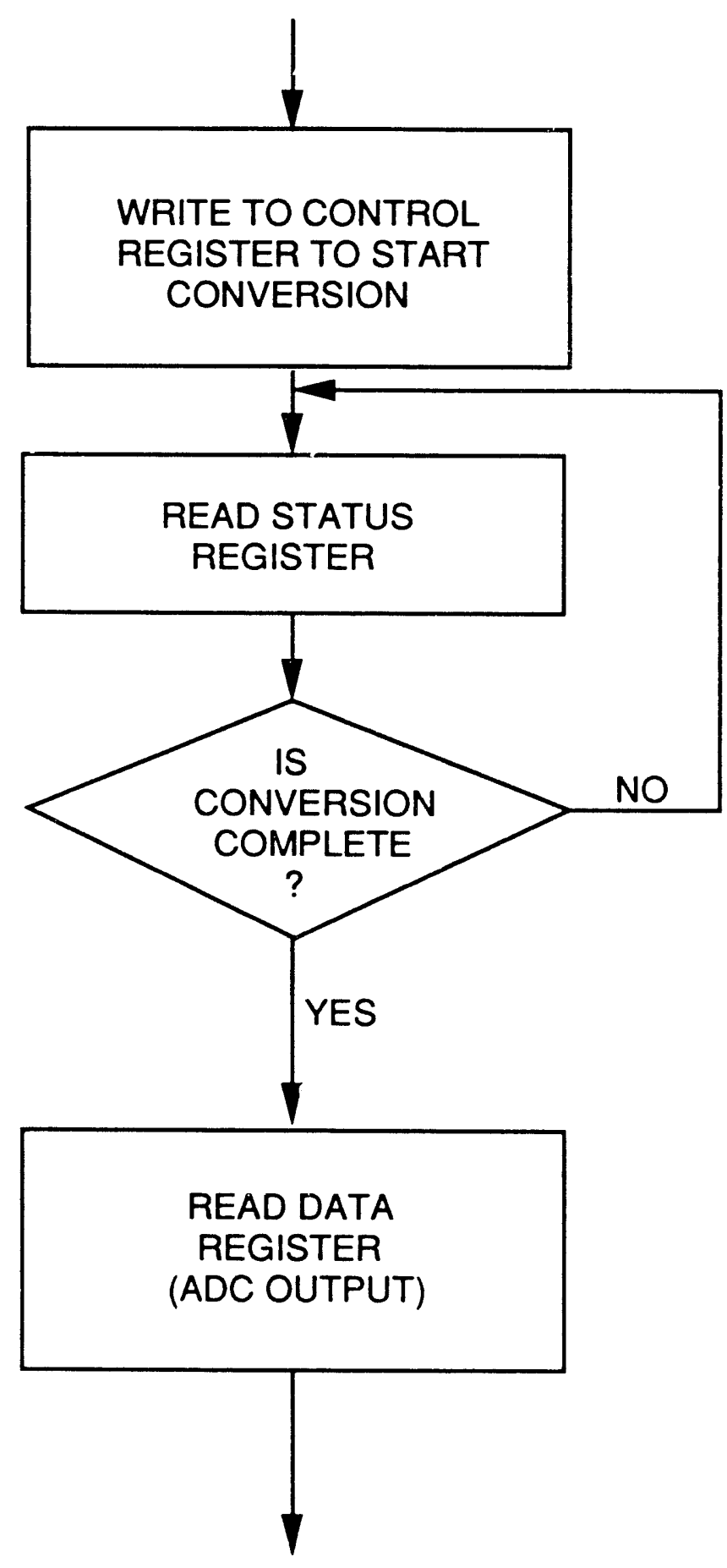




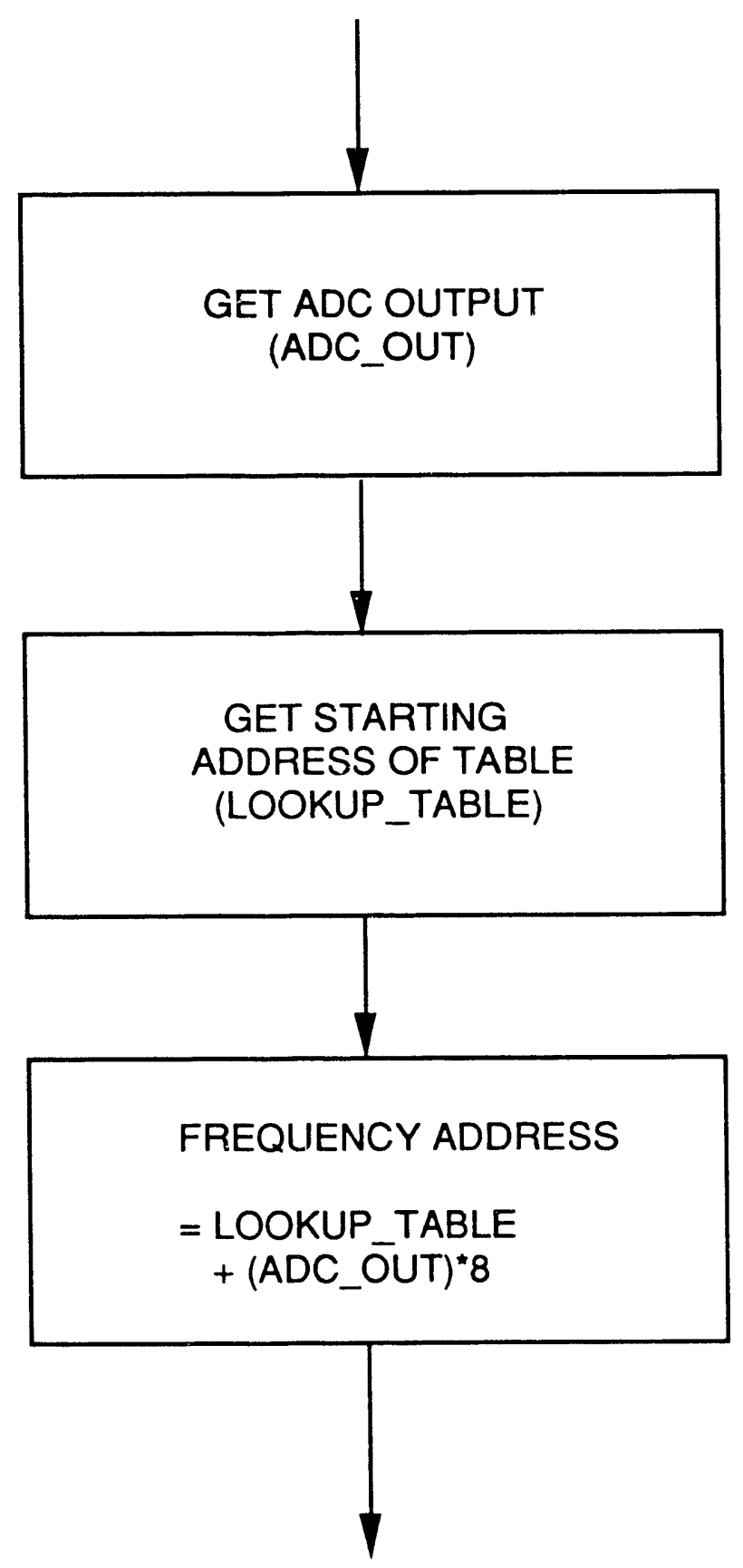




\section{PROGRAM SEGMENT}

Section to be executed continuously

$A D C$ output read with analog signal connected to channel $\varnothing$ START:

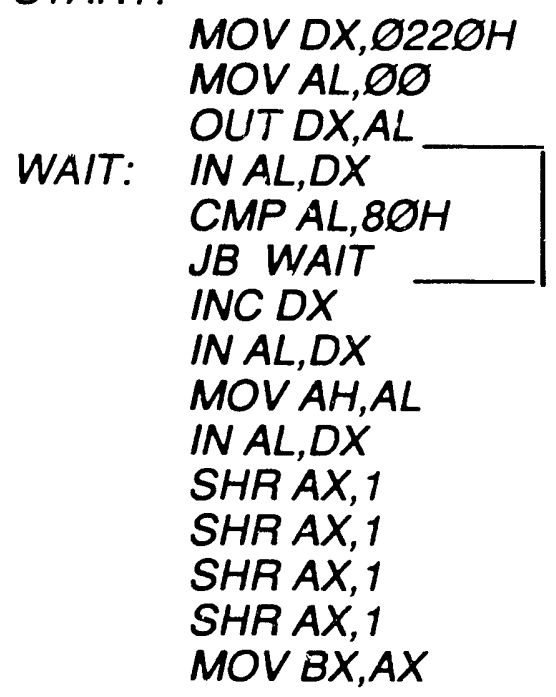
point at control register select channel $\varnothing$ send control word read status register and wait until conversion is complete read if not complete point at data register read data register, MSB read data register, $\lfloor S B$ "to reduce execution time $A X$ is
shifted 4 times instead of
doing in one instruction
using $C L "$
save $A D C$ output in $B X$

calculate frequency address from lookup table for the $A D C$ output read above

LEA SI,LOOKUP_TABLE
SHL BX,1
SHL BX,1
SHL BXं,
$A D D S I, B X$
point to beginning of table generate offset of frequency by multiplying $A D C$ output with 8 , then sum with $\mathrm{SI}$ to get the address

Frequency value sent to synthesizer, Model HP3325A.

MOV DX, 1 MOV CX,SYN_CHAR_2

AGAIN: MOV AH,

MOV AH,
MOV AL,[SI+7]

INT 17H

$D E C S I$

LOOP AGAIN

select printer

no. of characters to send

print character

get character in $A L$

BIOS call for print

point to next character

if more, continue

frequency unit sent to synthesizer, Model HP3325A

$\begin{aligned} & \text { LEA BX,FREQ_UNIT } \\ & \text { MOV CX,SYN_CHAR_3 } \\ \text { FZ1: } & \text { MOV AH, } \\ & \text { MOV AL,[BX] } \\ & \text { INT 17H } \\ & \text { INCBX } B X \\ & \text { LOOP FZ1 }\end{aligned}$

point at frequency unit no. of characters to send print character get character in $A L$ BIOS call for print point to next character if more, continue 


\section{INTERRUPT}

\section{A. INTERRUPT ROUTINE ADDRESS - Place in INTR. VECT. Table \\ B. INITIALIZE INTERRUPT CONTROLLER}

1. Control word and data port addresses

2. Control word and data word
a. Trigger-type (edge/level
b. $\quad$ Single or cascade
C ICW1
c. Type of interrupt
C ICW1
d. Slave code (cascade)
D ICW2
e. Mode selection
D ICW3
f. Unmask interrupt
D ICW4
D OCW1

* ICW - Initialization command word

OCW - Operation command word

C. INITIALIZE COUNTER/TIMER

1. Control register and counter addresses

2. Counter clock frequency

3. Control word and counter word
a. Select counter
b. Read/write option
c. Mode selection (out of 5)
d. Count type (binary/BCD)
e. Load counter with count
C
C
C
C
D

\section{INTERRUPT INTERVAL}

Depends on counter clock frequency.

For a clock frequency of $1.190 \mathrm{MHz}$, the range of interrupt interval is:

$$
0.8 \mu \mathrm{s}-55.1 \mathrm{~ms}
$$

Counter loaded with OFFFFH gives interval of $55.1 \mathrm{~ms}$. 


\section{INITIALIZATION FOR INTERRUPT}

define address of interrupt service

procedure, interrupt type 64

MOV AX,ØØØØH

MOV ES,AX

MOV WORD PTR ES:Ø1Ø2H, SEG ADC_FREQ_PROC

MOV WORD PTR ES: $10 \varnothing \mathrm{H}$, OFFSET ADC_FREQ_PROC

initialize interrupt controlier

MOV AL, $11 H$

MOV DX,2ØH

OUT DX,AL

MOV AL, $4 \varnothing H$

MOV DX,21H

OUT DX,AL

MOV AL,, $4 H$

OUT DX,AL

MOV AL, Ø1H

OUT DX,AL

MOV AL,ØFEH

OUT DX,AL

edge-triggered, cascade, ICW4 point at 8259 control

send ICW1

type 64 interrupt

point at ICW2 address

send ICW2

slave code

send slave code

ICW4, 8086 mode

send ICW4

OCW1 to unmask IRØ

send OCW1

initialize counter/timer for $1 \mathrm{kHz}$ output

command word for counter $\varnothing, L S B$ then $M S B$, square wave, $B C D$

MOV AL, 37H

MOV DX, $43 H$

OUT DX,AL

MOV AL, $58 \mathrm{H}$

MOV DX, $40 H$

OUT DX,AL

MOV AL,24H

OU'T DX,AL

8254 control word

point at control address

send control word

load LSB of count

point at counter $\varnothing$ addr.

send LSB of count

load MSB of count

send MSB of count 
RESULTS: EXECUTION TIME 


\section{EXECUTION TIME}

(10 MHz CPU)

The sampling interval of $10 \mu \mathrm{s}$ cannot be achieved unless the program segments such as ADC OUTPUT READ, FREQUENCY ADDRESS

CALCULATION and FREQUENCY SEND TO SYNTHESIZER are executed during $10 \mu \mathrm{s}$ interval. The execution time depends equally on hardware and software. The following table shows our results in terms of the execution times of the three program segments mentioned above. The following pages contain the information regarding the machine cycles of these program segments.

\section{Program Segment}

ADC OUTPUT READ

ADCUTPUTREAD
Execution Time

\footnotetext{
Including conversion time

Excluding conversion time

$35 \mu \mathrm{s}$

$5.2 \mu \mathrm{s}$

FREQUENCY ADDRESS CALCULATION

$2 \mu \mathrm{s}$

FREQUENCY SEND TO SYNTHESIZER

$36 \mathrm{~ms}$

The high execution times, such as $35 \mu$ s and $36 \mathrm{~ms}$, are mainly because of hardware being used. Also, we must note that the execution times are true for $10 \mathrm{MHz} C P U$. Even if we use higher speed CPU, still the ADC and the synthesizer we utilized here will not allow us to achieve the desired sampling rate. The next few pages will reveal how the hardware does slow down the process.
} 


\section{EXECUTION TIME}

(For $10 \mathrm{MHz}$ CPU)

MODULE: ADC OUTPUT READ

Execution time

Execution time without

the bracketed portion $-\quad 35 \mu \mathrm{s}$

$-\quad 5.2 \mu \mathrm{s}$

COMMENT: The execution time of the bracketed portion depends on the conversion time of the ADC.

Execution time is measured by executing the section of the program 1,000,000 times.

; $A D C$ output read >

START:

MOV DX,0220H

MOV AL,OO

OUT DX,AL

WAIT: IN AL,DX

CMP AL, $80 \mathrm{H}$

JB WAIT

INC DX

IN AL,DX

MOV AH,AL

IN AL,DX

SHR AX, 1

SHR AX, 1

SHR AX, 1

SHF AX, 1

MOV BX,AX
Machine Cycles

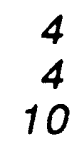

2

10

2

10

2

2

2

2

$\overline{52}$

Total number of machine cycles - 52

(Without marked portion) 


\section{EXECUTION TIME}

(10 MHz CPU)

MODULE: FREQUENCY ADDRESS CALCULATION

Execution time - $2 \mu \mathrm{s}$

COMMENT: Execution time was measured by executing this section $1,000,000$ times.

Hand-calculated machine cycles are shown below.

;

; calculate frequency address

; the $A D C$ output read above

LEA SI,LOOKUP_TABLE

SHL BX,1

SHL BX,1

$S H L B X, 1$

$A D D S I, B X$

Machine Cycles

7

2

2

2

3

;

16

Total number of machine cycles - 16 . 


\section{EXECUTION TIME}

MODULE: FREQUENCY SEND TO SYNTHESIZER

Execution time $\quad-\quad 36 \mathrm{~ms}$

COMMENT: Execution time for this section of the program was so high mainly because of large response time of the synthesizer.

;

; Froquency value sent to synthesizer

;

MOV DX, 1

MOV CX,SYN_CHAR_2

AGAIN: MOV AH,

MOV AL, $[S \mid+7]$

INT $17 H$

$D E C S I$

LOOP AGAIN

;

; frequency unit sent to synthesizer

; LEA BX,FREQ UNIT

MOV CX,SYN_CHAR_3

FZ1: MOV AH,,

MOV AL, [BX]

INT $17 H$

INC BX

LOOP FZ1

HP3325A response time:

Device time

Data transfer time

Device time for unit
- $\quad 2.8 \mathrm{~ms} /$ digit

- $\quad 250 \mu \mathrm{s} /$ digit

- $\quad 12.5 \mathrm{~ms}$

For 8 digits for frequency and unit

Total time $=(2.8+0.25) \times 8+12.5=36.9 \mathrm{~ms}$ 
SOLUTION: MEETING THE REQUIREMENTS

From the previous discussion and our results, it seems obvious that in order to meet our requirements we need to change the hardware. With the application of high-speed $A / D$ converter and frequency synthesizer, the execution time can be dramatically decreased. There is also room for reducing the execution time in software. All these are explained in this section. 


\section{EXECUTION TIME REDUCTION SCHEME}

\section{MODULE: ADC OUTPUT READ}

Use a high-speed A/D converter

Possible choice:

DT2831-G (Data Translation, Inc.)

12-bit resolution

16 input channel

* 2 us conversion time $250 \mathrm{KHz}$ A/D throughput
$100 \mathrm{M} \Omega$
Input Impedance (off/on channel)
$100 \mathrm{PF}$
Input Impedance (off/on channel)
$0-10 \mathrm{~V}$
Input range 


\section{EXECUTION TIME REDUCTION SCHEME}

\section{MODULE: FREQUENCY SEND TO SYNTHESIZER}

HARDWARE: Use a high-speed synthesizer

Possible choice:

VDS-15 (Citeq Electronics, Inc.)

$\mathrm{DC}-16 \mathrm{MHz}$ Frequency range

Remote Control

BCD Parallel - Input (38 bits)

$\leq 500$ ns - Switching Speed

PC Board

SOFTWARE: Use DOS function call instead of BIOS call.

DOS function call allows to send an entire string, rather than just a single character at a time as the BIOS INT 17H does.

\section{DOS FUNCTION CALL IMPLEMENTATION}

1. Load function No. $40 \mathrm{H}$ into $\mathrm{AH}$ register.

2. Load the DS register with the segment base.

3. Load the DX register with the offset of the string.

4. Load the $C X$ register with the number of bytes to write.

5. Load the $B X$ register with the file handle for the printer, $0004 \mathrm{H}$.

6. Execute INT $21 \mathrm{H}$.

* Create look-up table with unit.

EXPECTED EXECUTION TIME - $4-5 \mu \mathrm{s}(10 \mathrm{MHz}$ CPU) 
With the implementation of the proposed execution time reduction scheme, it will be possible to bring down the execution time of the segment of the program that is in continuous loop to within $15 \mu \mathrm{s}$ for a $10-\mathrm{MHz}$ CPU. Then further, if we use a reasonably higher speed CPU, the execution time can be kept below $10 \mu \mathrm{s}$. Then we can take samples of analog voltage every $10 \mu \mathrm{s}$. 


\section{APPENDIXA}

\section{PROGRAM LISTINGS}

Eilename

1. VOLT_FR1.ASM

2. VOLT_FR2.ASM

3. VOLT_FR3.ASM
Description

No interrupt, can be run in a continuous loop, look-up table is generated in ASCII.

Runs on interrupt basis, look-up table is generated in ASCII.

No interrupt, can be run in a continuous loop, look-up table is generated in $B C D$ ( $B C D$ is required by Citeq Synthesizer) 


\section{APPENDIX B}

Special Notes:

Three different programs are developed and the listings of these are attached to this report. These programs are also in the computer and on the diskette. The filenames and their functions are as follows:

Filename

VOLT_FR1.ASM

VOLT_FR2.ASM

VOLT_FR3.ASM
Function
a. No interrupt
b. Look-up table in ASCII
a. With interrupt
b. Look-up table in ASCII

a. No interrupt

b. Look-up table in $B C D$

\section{Directory}

DOS

DOS

DOS 


\section{INTERNAL DISTRIBUTION}

1. Central Research !_ibrary

2. Document Reference

3-4. Laboratory Records

5. Laboratory Records, R.C.

6. ORNL Patent Office

7. $Y-12$ Technical Library

8. G. D. Alton

9. J. B. Ball

10. D. T. Dowling

11. D. L. Haynes

12. C. M. Jones

13. R. C. Juras

14. S. N. Lane

15. M. J. Meigs

16. G. D. Mills

17-19. S. W. Mosko

20. D. K. Olsen

21. B. A. Tatum

\section{EXTERNAL DISTRIBUTION}

22. Dr. A. M. Hasanul Basher, School of Engineering Technology, South Carolina State College, Orangeburg, SC 29117

23. J. T. Crockett, Jr., Director, Faculty and HBCU Programs, ORAU, Energy Bldg., Room OB-9, Oak Ridge, Tennessee 37831

24. Assistant Manager, Energy Research and Development, DOEOR

25-26. Office of Scientific and Technical Information, P. O. Box 62, Oak Ridge, TN 37831 

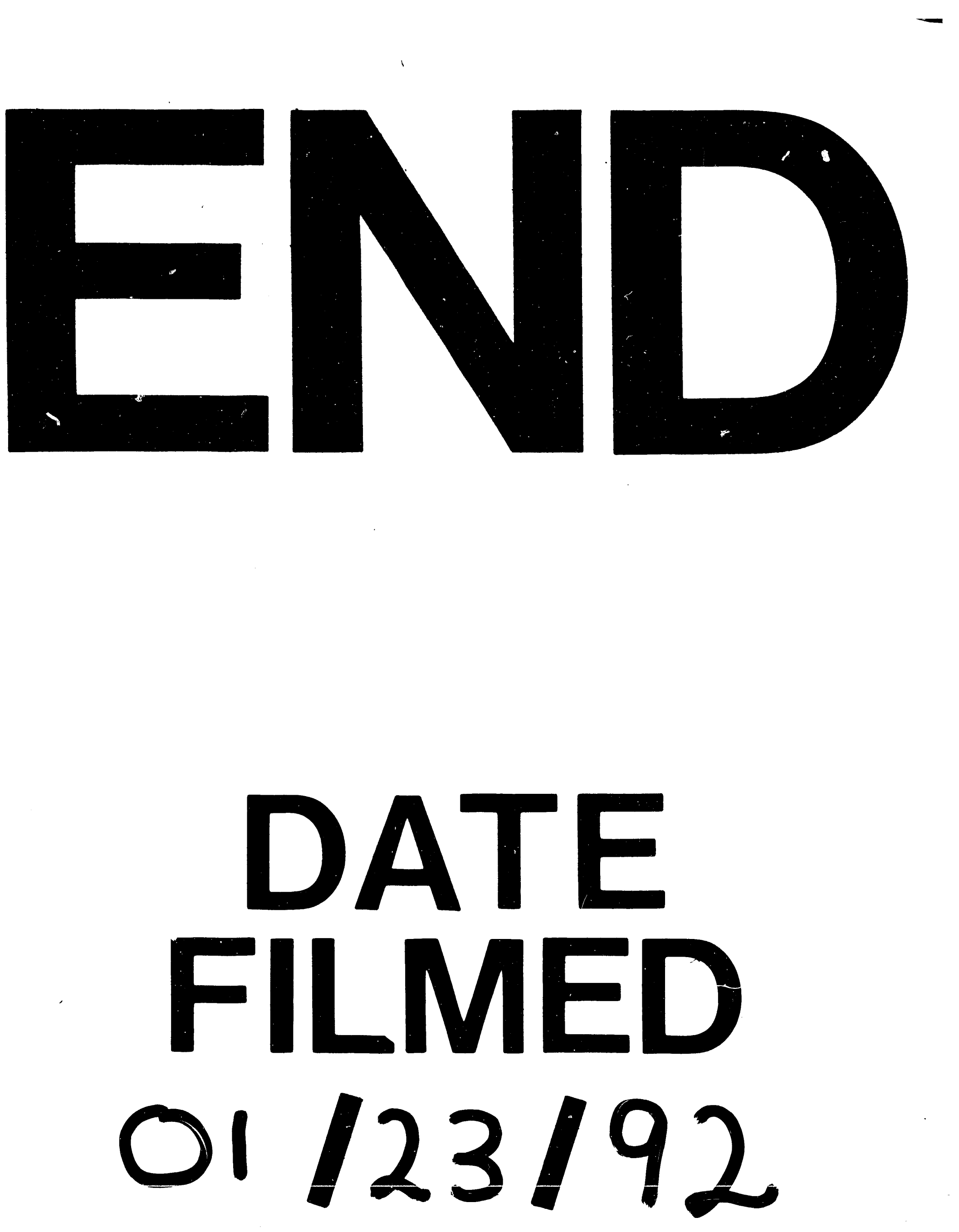

7 


$$
\because
$$

